\title{
DUMPING SOCIAL COMO INSTRUMENTO DE PRECARIZAÇÃO DOS DIREITOS TRABALHISTAS NO BRASIL: NECESSIDADE DE REGULAMENTAÇÃO
}

\section{Nayara Passos Alves lara Marthos Águila}

ISSUE DOI: $10.21207 / 1983.4225 .272$

\section{RESUMO}

O presente artigo aborda o tema do dumping social e sua possibilidade de regulamentação pelos organismos internacionais, tais como Organização Mundial do Comércio (OMC) e a Organização Internacional do Trabalho (OIT). Para melhor desenvolvimento do tema, o artigo trata da globalização e seus reflexos perante o comércio internacional, com as consequentes mudanças que esse fenômeno trouxe no contexto dos países. O dumping é uma prática comercial desleal em que empresas transnacionais exploram a mão-de-obra dos países em desenvolvimento, afetando sobremaneira os direitos trabalhistas. A origem do dumping social e sua dinâmica é alvo de preocupação no cenário mundial, razão pela qual devem ser discutidas propostas de sua regulamentação, resolvendo-se então o impasse através de ideias dos países desenvolvidos e subdesenvolvidos. Além do contexto histórico no qual surgem as referidas propostas, são apresentados e discutidos 
por meio de técnica de pesquisa bibliográfica os posicionamentos favoráveis e contrários à adoção de referidas medidas, bem como os empecilhos que se apresentam no caminho da resolução desse impasse.

Palavras-chave: comércio internacional. dumping social. regulamentação. precarização de direitos trabalhistas.

\section{INTRODUÇÃO}

No decorrer do tempo, o processo produtivo foi objeto de grandes transformações, sendo que, após a Revolução Industrial, a produção industrial passou a dominar a economia e as relações de trabalho. $\mathrm{O}$ crescimento da economia se expandiu além das fronteiras de cada país e provocou o aumento da concorrência entre as empresas, surgindo empresas multinacionais e transnacionais.

A internacionalização do sistema capitalista, caracterizada pela expansão da indústria que ultrapassou as fronteiras econômicas dos Estados, dá origem ao fenômeno da globalização e concorrência entre empresas no cenário mundial.

Os efeitos da globalização aprofundam a exclusão social e permitem o surgimento do dumping social no âmbito trabalhista, no sentido de que, a concorrência desleal das empresas, notadamente multinacionais e transnacionais, na busca desenfreada pelo lucro impõe às empresas locais a redução do custo da produção, atingindo direitos trabalhistas e precariezando as relações de trabalho.

O fenômeno da globalização fez com que organismos internacionais, como a Organização Mundial do Comércio (OMC) e a Organização Internacional do Trabalho (OIT) levassem à discussão as matérias trabalhistas com o intuito de se evitar a prática do dumping social.

No Brasil, a falta de previsão legal específica tem sido usada como fundamento para não punir empresas que praticam o dumping social trabalhista. Nesse contexto, a regulamentação é necessária para a condenação de empresas pela prática de dumping social trabalhista e, via de consequência, amenizar as discordâncias doutrinárias e jurisprudenciais sobre o tema. Enquanto forem ignorados os malefícios do dumping, os trabalhadores brasileiros permanecerão sendo explorados e submetidos à condições degradantes de trabalho. 
Não obstante a ausência de regulamentação específica no Direito do Trabalho brasileiro, muitos juízes do trabalho se sensibilizam com o dano provocado pelo dumping trabalhista, e, por meio uma análise sistemática de outros dispositivos do ordenamento jurídico, condenam as empresas que insistem em desrespeitar, de forma reiterada, os direitos trabalhistas.

Ainda dentro da jurisprudência que concorda com a condenação da empresa no pagamento da indenização pela prática de dumping social, existem várias divergências de entendimento sobre a legitimidade para propor a ação, o destino do valor da indenização e a possibilidade de concessão da indenização ex ofício.

O Direito do Trabalho brasileiro possui maturidade necessária para solucionar as questões que lhe são apresentadas sobre dumping, contudo, a regulamentação representa a segurança jurídica necessária para o desenvolvimento das relações de trabalho.

\section{O COMÉRCIO INTERNACIONAL E AS RELAÇÕES TRABALHISTAS}

O modo de operacionalizar o trabalho ganhou nova feição com o passar do tempo, com mudanças nítidas, desde a escravidão até os dias atuais.

No sistema capitalista, maximizado com a Revolução Industrial, houve a busca incessante de lucro e aumento de capital, traduzida na ideia de uma classe dominadora, os donos das empresas e das fábricas, e de uma classe enfraquecida, representada pelos trabalhadores e denominada proletariado, sendo que a relação estabelecida entre essas classes é caracterizada pela troca da força do trabalho pelo salário.

Os efeitos da Revolução Industrial e do liberalismo econômico trouxeram a liberdade de contratar no âmbito das relações do trabalho e, como consequência, a exploração e degradação das condições humanas nos aspectos laborais, como forma de competir no mercado econômico e gerar maior lucratividade às empresas.

As transformações tecnológicas, o desenvolvimento da indústria e a expansão do capitalismo, bem como a expansão mercantilista, são fatores que possibilitaram a busca por mais lucratividade do mercado, inclu- 
sive com a transferência da produção para outros centros regionais que permitem menor custo da produção e aumento da lucratividade. Surge, então, o fenômeno da globalização da economia, com a interdependência entre os países, e consequente internacionalização da economia.

\subsection{A globalização e sua consequência perante as relações de trabalho internacional: o surgimento do dumping}

Arion Sayão Romita ${ }^{1}$ identifica a globalização em quatro fases. A primeira no Império Romano, a segunda nos séculos XIV e XV, a terceira reapareceu no século XIX, coincidentemente à fase do liberalismo econômico e por fim, após a Segunda Guerra Mundial, correspondente à globalização contemporânea.

Para o citado autor, globalização seria "um conjunto de fatores que determinaram a mudança dos padrões de produção, criando uma nova divisão internacional do trabalho.".2

A influência das grandes empresas fez com que antigas fronteiras ou barreiras protecionistas fossem mitigadas por um aparente mercado livre e sendo assim, as limitações nacionais e internacionais tornaram-se indefinidas.

A globalização alterou substancialmente as relações sociais, pelo fato da tecnologia ter trazido consigo um processo de forte transação comercial e financeira entre todos os países, advindo daí uma desregulamentação da economia mundial, por permitir que barreiras fossem quebradas e que as distâncias fossem diminuídas, permitindo uma competitividade cada vez maior.

Entre tantos outros efeitos gerados pela globalização está a migração das indústrias dos países desenvolvidos para os emergentes, a descentralização das atividades empresariais, fenômeno conhecido como terceirização e a informatização das relações laborais.

\footnotetext{
${ }^{1}$ ROMITA, Arion Sayão. Globalização da economia e direito do trabalho. São Paulo: LTr, 1997. p. 8.

${ }^{2}$ Idem. p. 29.
} 
Para Alice Monteiro de Barros "o fenômeno da terceirização consiste em transferir para outrem atividades consideradas secundárias, ou seja, de suporte, atendo-se a empresa à sua atividade principal ". ${ }^{3}$

A terceirização, ou melhor, a subcontratação dos serviços, é uma resposta à necessidade de buscar soluções para a redução do custo da produção. Uma das alternativas encontradas pelos empresários, como reflexo da globalização, foi a transferência da produção para países subdesenvolvidos, onde a mão de obra é abundante e barata.

As empresas buscam concentrar suas atividades em países em desenvolvimento, onde há pouca proteção trabalhista, tendo em vista que isso é fator determinante para a exploração da mão de obra e o pagamento de salários ínfimos.

A redução das fronteiras ou barreiras alfandegárias entre os países colaborou sobremaneira para o surgimento do dumping.

Welber Barral designa a ocorrência do dumping "quando o preço de exportação de um bem é inferior ao preço de venda do mercado exportador. Para ser condenável, esta diferença de preços (margem de dumping) deve causar um dano material à indústria do país importador." 4

Com o avanço da economia internacional, a livre concorrência mundial foi afetada e, sendo assim, vários empregadores objetivando garantir a estabilidade de suas empresas diante de tantas outras multinacionais, buscaram reduzir os custos com a mão de obra operária através da redução e até mesmo da exclusão dos direitos fundamentais dos trabalhadores ${ }^{5}$.

O fenômeno da Revolução Industrial aliado ao processo de globalização e ao desenvolvimento tecnológico iniciado no século XIX provocou intensas mudanças nas relações laborais, principalmente no que tange à qualidade de vida do trabalhador, pois o que se vivencia é a precarização das condições de trabalho através da exploração da mão de obra operária e dos constantes desrespeitos à legislação trabalhista, configurando-se o dumping social.

\footnotetext{
${ }^{3}$ BARROS, Alice Monteiro de. Curso de direito do trabalho. São Paulo: LTr, 2005. p. 424.

${ }^{4}$ BARRAL, Welber. Dumping e comércio internacional: a regulamentação antidumping após a rodada do Uruguai. Rio de Janeiro: Forense, 2000. p. 125.

${ }^{5}$ Idem. p. 200.
} 


\section{DUMPING SOCIAL}

Em uma abordagem geral, dumping é a prática da concorrência desleal consubstanciada no cenário mundial e destaca-se pela colocação de um bem no mercado externo com preço de exportação abaixo do valor normal praticado no mercado interno do país exportador. Essa prática sempre foi condenada como a responsável pela violação das regras dos mercados trabalhistas, surgindo primeiro internamente dentro de alguns países e após, expandindo pelo cenário mundial.

Importante destacar que foram os economistas e não os juristas os primeiros a definirem o que é o dumping social.

De acordo com Luiz Olavo Baptista:

A expressão dumping vem do inglês, to dump, cuja significação original era to drop or let fall in mass, ou to unload or empty out, passando depois para a significação de "colocar mercadorias no mercado em grande quantidade e a preços muito baixos", fazendo com que os preços caíssem 6 .

Em relação à visão jurídica, o dumping é uma espécie de ilícito na esfera da legislação do comércio internacional assim como no direito interno. Tal ilícito internacional foi configurado pelo Acordo Geral de Tarifas e Comércio (GATT), ao qual o Brasil aderiu na sua ordem jurídica interna.

Ainda, conforme ensina Luiz Olavo Baptista:

Segundo as regras da OMC, um produto é dumped quando o seu preço de exportação for menor que o seu valor normal. A determinação do que é o valor normal depende das contigências do país exportador ou importador; em geral o cálculo do valor normal baseia-se no preço praticado usualmente no país exportador ou no preço de exportação para um terceiro país, ou ainda nos custos de produção no país

\footnotetext{
${ }^{6}$ BESELER J. F.; WILLIAMS A. N. Anti-dumping and anti. subsidy law. apud BAPTISTA, Luiz Olavo. OMC e o comércio internacional: dumping e anti-dumping no Brasil. São Paulo: Aduaneiras, 2002. p. 29.
} 
de origem da mercadoria, ou no país de destino da mesma. Por isso a definição jurídica não se restringe à discriminação de preços entre os mercados nacionais afetados, como a adotada pela teoria econômica, nem inclui todas as formas de discriminação de preços praticados internacionalmente. Assim, o conceito de dumping da OMC é essencialmente amplo e cobra várias práticas diversas. Em consequência, vários autores procuram definir o dumping pelo que não é considerado parte dessa prática ${ }^{7}$.

A prática do dumping vem causando prejuízos às indústrias implantadas no país importador, podendo retardar o estabelecimento de uma indústria nacional e com isso afetar a livre concorrência.

Para a OMC, as normas que vão conceituar o dumping estão previstas no Acordo sobre a Implementação do Artigo VI do GATT-1994 e do Acordo sobre Subsídios e Medidas Compensatórias do GATT-1994. O parágrafo $1 .^{\circ}$, do artigo $2 .^{\circ}$, do Acordo sobre a Implementação do Artigo VI do Gatt 1994, estabelece que:

Há dumping quando a oferta de um produto no comércio de outro país a preço inferior, a seu valor normal, no caso de o preço de exportação do produto ser inferior àquele praticado, no curso normal das atividades comerciais, para o mesmo produto destinado ao consumo no país exportador.

Com a intensificação do comércio internacional, surgiu o dumping social, originário do dumping.

Marcelo Barroso Kümer ${ }^{8}$ indica que esse quadro gera uma competitividade desleal devido ao desrespeito aos direitos trabalhistas fundamentais. O dumping social se caracteriza pelo lucro que determinado país

\footnotetext{
${ }^{7}$ BESELER J. F.; WILLIAMS A. N. Anti-dumping and anti. subsidy law. apud BAPTISTA, Luiz Olavo. OMC e o comércio internacional: dumping e anti-dumping no Brasil. São Paulo: Aduaneiras, 2002. p. 31.

${ }^{8}$ KÜMER, Marcelo Barroso. As convenções da OIT e Mercosul. LTr: São Paulo, 2001. p. $75-76$.
} 
tem em relação ao preço de seus produtos no mercado internacional em razão de ínfimos padrões trabalhistas.

O dumping social sempre esteve dissipado no comércio exterior e se caracteriza pelas reiteradas condutas que violam os direitos trabalhistas e os direitos humanos dos trabalhadores, direitos estes inerentes à integridade de qualquer pessoa. A jurisprudência vem denominando assim a conduta de dumping social:

INDENIZAÇÃO POR DUMPING SOCIAL. Tendo a reclamada agido de forma reiterada e sistemática na precarização e violação de direitos, principalmente os trabalhistas, o entendimento referente à indenização por dano social é plenamente aplicável e socialmente justificável para a situação que estabeleceu na presente demanda. Dessa forma, afigura-se razoável, diante da situação verificada nos autos, que a reclamada seja condenada ao pagamento de indenização a título de dumping social (TRT $4 .^{\mathrm{a}}$ Região). ${ }^{9}$

As empresas, ao praticarem o dumping social, desrespeitam os direitos trabalhistas mínimos previstos na Constituição Federal, os quais são garantidos a qualquer trabalhador.

Desrespeitando os direitos trabalhistas dos empregados, os empresários atingem tanto a ordem patrimonial quanto a esfera pessoal dos empregados, comprometendo assim a ordem social.

A prática do dumping social vem afetando sobremaneira o princípio da livre concorrência, já que as empresas atuam em condições de desigualdade com as demais pertencentes ao mesmo ramo, explorando mãode-obra sem arcarem com o prejuízo daí resultante, consubstanciando, então, a concorrência desleal.

É nítido perceber que a prática reiterada e inescusável do dumping social vem gerando danos aos direitos do trabalhador e à própria sociedade, uma vez que afeta a estrutura do Estado social e do próprio modelo

\footnotetext{
${ }^{9}$ BRASIL. Tribunal Regional do Trabalho da $4 .^{a}$ Região. Recurso Ordinário n. ${ }^{\circ} 0131000$ 63.2009.5.04.0005 RS. Relator Desembargador Ricardo Carvalho Fraga. Data de Julgamento: 08/06/2011. Vara de Origem: Quinta Vara do Trabalho de Porto Alegre.
} 
capitalista, tendo em vista a obtenção de vantagem indevida perante a concorrência.

\subsection{O dumping social e o papel de organizações internacionais para a regulamentação}

Considerando que o dumping está inserido originalmente no contexto do comércio internacional, os organismos internacionais objeto de análise são o Acordo Geral de Tarifas e Comércio (GATT) e a Organização Mundial do Comércio (OMC). O dumping social reflete nas relações de trabalho, razão pela qual a Organização Internacional do Trabalho (OIT) apresenta papel fundamental.

O GATT visa regular o comércio internacional, tendo como base o princípio da liberdade de negociar e foi firmado, a princípio, em 30 de outubro de 1947, na cidade de Genebra, por 23 países. O Brasil foi um dos signatários do GATT e esse integra a legislação brasileira.

O GATT trata da redução das tarifas alfandegárias e, por consequência, da abertura comercial entre os países. Dentre as principais regras abordadas, está o Tratamento da Nação Mais Favorecida - NMF, o qual proíbe discriminação entre países, sendo que vantagens concedidas a um país deverão ser concedidas aos demais; a do tratamento nacional, a qual estipula que os produtos adentrados às fronteiras do Estado, devem ser tratados no Estado como se fossem nacionais e a redução de barreiras tarifárias por meio de negociações coletivas ${ }^{10}$.

Através do GATT foram empreendidas diversas rodadas de negociações, sendo a mais importante a Rodada do Uruguai (1986-1994), que culminou no surgimento da OMC, formalizada pela Declaração de Marraquech, de 15 de abril de 1994.

Segundo Ricardo Seitenfus ${ }^{11}$ após o Acordo de Marrakesh, em 1994, o GATT desapareceu e a OMC surgiu como herdeira dos compromissos assumidos, representando uma instituição especializada e autônoma das Nações Unidas. A OMC surgiu, então, para reiterar os objetivos do

\footnotetext{
${ }^{10}$ THORSTENSEN. Vera. OMC - Organização Mundial do Comércio: as regras do comércio internacional e a rodada do milênio. São Paulo: Aduaneiras, 1999. p. 100.

${ }^{11}$ SEITENFUS, Ricardo. Manual das organizações internacionais. Porto Alegre: Livraria do Advogado, 1997. p. 159.
} 
GATT, ou seja, incrementar a produção e o comércio de bens e serviços, trabalhar para assegurar o pleno emprego e aumentar os níveis de vida das populações dos países membros ${ }^{12}$.

A Rodada do Uruguai também estabeleceu medidas antidumping e fez ressurgir a ideia de regulamentar o comércio internacional, em matéria de bens e serviços. Importantes questões vieram à tona e a preocupação com as questões trabalhistas surgiram. Contudo, pela forte resistência dos países em desenvolvimento, a proposta dos EUA em estabelecer um padrão de condição de trabalho na OMC restou frustrada ${ }^{13}$, sob a acusação de que os Estados Unidos estariam camuflando propósitos protecionistas por trás dessa proposta de padronização das condições trabalhistas.

Em dezembro de 1996, aconteceu a Rodada de Cingapura (primeira Conferência Ministerial da OMC) e o tema dumping social foi objeto de dois documentos - um proposto pelos Estados Unidos e o outro pela Noruega. O documento americano trazia o exame de normas trabalhistas, dando direito à organização, à livre associação e à reivindicação coletiva, proibição de trabalho forçado, eliminação de formas de exploração de trabalho infantil e não discriminação em empregos ou ocupação. A Noruega já se preocupava em elevar as condições trabalhistas mundiais ${ }^{14}$. Novamente os países em desenvolvimento, principalmente o Brasil, foram fortemente contrários a esta ideia.

Para os países em desenvolvimento a matéria trazida à discussão pelos Estados Unidos, de criar padrões de relações trabalhistas mais equilibrados, deveria ser atribuição da Organização Internacional do Trabalho (OIT) e não da OMC, eis que a primeira foi criada para resolver controvérsias trabalhistas. ${ }^{15}$

A Organização Internacional do Trabalho (OIT) foi criada em 11 de abril de 1919. Sua atividade principal está consubstanciada no trabalho

\footnotetext{
${ }^{12}$ SEITENFUS, Ricardo. Manual das organizações internacionais. Porto Alegre: Livraria do Advogado, 1997. p. 159.

${ }^{13}$ THORSTENSEN. Vera. OMC - Organização Mundial do Comércio: as regras do comércio internacional e a rodada do milênio. São Paulo: Aduaneiras, 1999. p. 157.

14 THORSTENSEN, Vera. OMC - Organização Mundial do Comércio: as regras do comércio internacional e a nova rodada de negociações multilaterias. 2. ed. São Paulo: Aduaneiras, 2001. p. 163.

${ }^{15}$ SEITENFUS, Ricardo. Manual das organizações internacionais. Porto Alegre: Livraria do Advogado, 1997. p. 200.
} 
técnico e progressiva tomada de consciência para a defesa da dignidade do trabalhador. A OIT visa à melhoria das condições socio-laborais mundiais.

Em 1944, na 26. ${ }^{a}$ Conferência na Filadélfia (EUA), a OIT apresentou de forma clara os princípios e propósitos que deveriam guiar a nova fase da organização. Ricardo Seitenfus ${ }^{16}$ assim os enumera: o trabalho não deve ser tratado como uma mercadoria; a liberdade de expressão e de associação constitui condição indispensável para o progresso; a pobreza, onde quer que esteja, constitui uma ameaça para a prosperidade de todos; a luta contra as necessidades deve ser feita com o máximo de energia no seio de cada Nação através de um contínuo e concentrado esforço internacional em que os representantes dos trabalhadores e os empregadores, cooperando em pé de igualdade com os Governos, participem de discussões livres e de decisões de caráter democrático com o objetivo de promover o bem comum; todos os seres humanos, de qualquer raça, religião ou sexo, têm o direito de conseguir o seu progresso material e seu desenvolvimento espiritual em liberdade, dignidade, em segurança econômica e comum igualdade de chances.

Na Conferência Internacional do Trabalho, em 1994, foi discutida a proposta de inserção de cláusula social na OMC. Esta cláusula objetivava a aplicação de sanções comerciais ou exclusão da OMC para países que não implementassem algumas convenções da OIT. A proposta foi desconsiderada ${ }^{17}$.

Os países em desenvolvimento foram fortemente contrários à ideia de inclusão das cláusulas sociais na OMC, pois isso refletiria a adoção do protecionismo por parte dos países desenvolvidos. A grande polêmica surgida em torno da questão da inclusão de cláusulas sociais na OMC levou à conclusão pela colaboração entre a OMC e a OIT.

O debate foi retomado na Conferência Ministerial de Seattle, em 1999, quando algumas recomendações foram importantes, dentre as quais: iniciar uma análise da relação entre padrões trabalhistas e comércio; estabelecer um grupo de trabalho para temas comerciais relacionados aos padrões trabalhistas, objetivando trocar informações e promover um inter-

\footnotetext{
${ }^{16}$ SEITENFUS, Ricardo. Manual das organizações internacionais. Porto Alegre: Livraria do Advogado, 1997. p. 162.

17 THORSTENSEN, Vera. OMC - Organização Mundial do Comércio: as regras do comércio internacional e a nova rodada de negociações multilaterias. 2. ed. São Paulo: Aduaneiras, 2001. p. 163.
} 
câmbio entre OMC, OIT e outras organizações internacionais de temas sociais. A OIT foi considerada o foro competente para tratar das questões trabalhistas e pelo fato da matéria não ser comercial, não deverá ser tratada na $\mathrm{OMC}^{18}$.

A polêmica sobre a regulamentação do dumping social e aplicação de sanções pela OMC ou pela OIT reside no questionamento sobre a competência da OMC para tratar de assunto afeto às relações de trabalho e não diretamente ao comércio. Há os que apostam na regulamentação do dumping social pela OMC, pois apenas ela tem o poder de sanção que seria necessário para coibir esta prática. Outros sustentam que a regulamentação deve ser realizada pela OIT, pois ela seria competente para tratar dos assuntos trabalhistas em âmbito internacional. No entanto, os críticos deste último posicionamento apontam que a OIT não é dotada de poder coercitivo, fundamental para resolver esta problemática ${ }^{19}$.

A regulamentação do dumping social na OMC divide opiniões. Reinaldo Gonçalves assim preceitua:

A OMC tem uma vantagem extraordinária sobre a OIT no que diz respeito à aderência institucional. No caso da OMC, no momento em que o país torna-se membro da organização ele é automaticamente parte contratante de todos os acordos assinados no âmbito da organização ${ }^{20}$.

Jete Jane Fiorati e Ana Carolina Marossi Batista ${ }^{21}$ justificam que a OMC é a organização mais indicada para a regulamentação jurídica do dumping social. Afinal, qualquer prática discriminatória pode afetar os objetivos de se assegurar a competição global.

\footnotetext{
${ }^{18}$ Wto, 1999, Checklist of Isuues. Disponível em: 〈www.wto.org〉. Acesso em: 20. Jul. 2013.

${ }^{19}$ Recommendations of the task force on aid for trade. (Recomendações do grupo de trabalho sobre a ajuda ao comércio) Disponível em: 〈www.wto.org〉. Acesso em: 20. Jul. 2013.

${ }^{20}$ GONÇALVES, Reinaldo. O Brasil e o comércio internacional: transformações e perspectivas. São Paulo: Contexto, 2000. p. 63.

${ }^{21}$ FIORATI, Jete Jane; BATISTA, Ana Carolina Marossi. Dumping social e sua disciplina no direito internacional. Revista de Estudos Jurídicos UNESP - Revista da Universidade Estadual Paulista. Franca, n. 10, ano 6, jan - dez 2001. p. 167.
} 
A defesa daqueles que indicam a OMC como competente para regulamentar o dumping social é que a OIT não teria poder para sancionar os países que violam seus acordos. $\mathrm{O}$ maior argumento daqueles que defendem a regulamentação do dumping social pela OMC é que esta trata das relações comerciais e tem o poder coercitivo, ou seja, tem o poder de impor sanções aos países vinculados aos seus acordos.

Por outro lado, a grande dificuldade é que inexiste na história do GATT e na OMC uma relação de temas sociais ou trabalhistas.

A divisão de posicionamento reside no fato de que na OMC seriam discutidas propostas somente do ponto de vista comercial. No entanto, é certo que a expansão do comércio exige a expansão da abrangência do tema dentro da OMC.

Nesse sentido salienta Vera Thorstensen:

Os agora chamados "novos temas" estão se convertendo em pontos de sérios conflitos no comércio internacional e exigindo a atenção da OMC, que passou a analisá-la nos seus diversos conselhos e comitês, além de criar vários grupos de trabalho para examiná-los. São eles: investimentos, concorrência, transparência das compras governamentais, facilitação do comércio, comércio eletrônico, medidas ambientais e padrões trabalhistas que afetam o comércio ${ }^{22}$.

Alberto do Amaral Júnior ${ }^{23}$ lista algumas dificuldades de listar a OMC como foro para tratar a cláusula social: a OMC não conta com programas de cooperação técnica que possibilitaria o desenvolvimento econômico desses países, o que não desencadearia a melhora nos padrões trabalhistas nacionais e evidenciaria o protecionismo das nações desenvolvidas, as quais se utilizariam da OMC para não perderem vantagens comerciais.

22 THORSTENSEN, Vera. OMC - Organização Mundial do Comércio: as regras do comércio internacional e a nova rodada de negociações multilaterais. 2. ed. São Paulo: Aduaneiras, 2001. p. 499.

${ }^{23}$ AMARAL JÙNIOR, Alberto do. Padrões trabalhistas e comércio internacional: renasce o protecionismo? In: BASSO, Maristela; PADRO, Maurício; ZAITZ, Daniela (ORG.). Direito do comércio internacional: pragmática, diversidade e inovação. Estudos em homenagem ao Professor Luiz Olavo Baptista. 2. tiragem. São Paulo: Juruá, 2006. p. 54. 
Tal instituição não conta com o apoio de todos os Estados-Membros, encontrando forte oposição dos países em desenvolvimento. A OMC é eminentemente comercial, não sendo o caso de atribuir a ela assuntos trabalhistas, que poderia causar iniciativas protecionistas comprometendo todo o sistema multilateral de comércio internacional. Por fim, tratar o tema como simples prática desleal do comércio seria compará-lo a expedientes econômicos voltados puramente ao aumento da concorrência, reduzindo toda a complexidade do assunto e vizualizando-o como obstáculo à realização da dignidade humana, visto tratar-se de direito fundamental e estar intimamente ligado à temática dos direitos humanos. Por isso que a alternativa apontada pelos defensores da OIT como órgão destinado a regulamentar a questão é dar mais força política a tal instituição.

Para resolver o impasse, a solução então é a cooperação entre OMC e OIT, e conforme analisa Daniel S. Ehrenber ${ }^{24}$, a primeira atuaria quando se tratasse de cooperação técnica e supervisão, enquanto a OMC colaboraria em matérias como práticas desleais do comércio, com seu Sistema de Solução de Controvérsias e com o procedimento para implementar as decisões.

Logo, a OMC iria analisar os impactos comerciais e a OIT verificaria as infrações aos direitos trabalhistas.

De todo modo, para eliminar ou mesmo reduzir a concorrência internacional pautada no dumping social faz-se necessária a regulamentação da matéria e, neste aspecto, as cláusulas sociais seriam imprescindíveis.

Alberto Amaral Júnior ${ }^{25}$ pondera que a cláusula social é a associação entre direitos trabalhistas e comércio. Ele aponta quatro dimensões deste impasse: a preocupação com as práticas desleais de comércio; a busca de soluções que reduzam os níveis de desemprego nas economias que sofrem as consequências do processo de globalização; expansão do desconforto ético e moral com a violação dos direitos humanos e o temor de que

24 An ILO-GATT/WTO Enforcement Regime for International Labor Rights. apud. BASSO, Maristela; PADRO, Maurício; ZAITZ, Daniela (ORG.). Direito do comércio internacional: pragmática, diversidade e inovação. Estudos em homenagem ao Professor Luiz Olavo Baptista. 2. tiragem. São Paulo: Juruá, 2006. p. 54-55.

${ }^{25}$ AMARAL JÙNIOR, Alberto do. Padrões trabalhistas e comércio internacional: renasce o protecionismo? In: BASSO, Maristela; PADRO, Maurício; ZAITZ, Daniela (ORG.). Direito do comércio internacional: pragmática, diversidade e inovação. Estudos em homenagem ao Professor Luiz Olavo Baptista. 2 tiragem. São Paulo: Juruá, 2006. p. 48. 
tais argumentos favorecerão o protecionismo, afetando as exportações dos países em desenvolvimento.

Conforme Roberto Di Sena Júnior:

A expressão claúsula social serve para designar a inclusão, em tratados internacionais de comércio, de normas de proteção ao trabalhador. Essas normas, ao disciplinarem as condições de trabalho e as relações capital-trabalho, estabelecem padrões laborais mínimos a serem observados pelas empresas exportadoras. Em síntese, claúsula social busca garantir "padrões trabalhistas" internacionalmente aceitos e assegurar que os trabalhadores não sejam prejudicados pela ânsia empresarial de tornar seus produtos mais baratos e, por conseguinte, mais competitivos ${ }^{26}$.

As cláusulas sociais podem ser inseridas no contexto internacional pelas Organizações já mencionadas, contribuindo para proteger as relações trabalhistas, cada vez mais corroídas pela prática do dumping social.

\subsection{Dumping social, livre concorrência e cláusulas sociais}

A prática do dumping social institucionalizou-se e disseminou-se por todo o cenário global. Seus efeitos são devastadores para o comércio exterior, pois, além de desrespeitar os direitos humanos fundamentais, esse fenômeno contribui largamente para a concorrência desleal no mercado mundial. Trata-se de um tema complexo que envolve tanto aspectos econômicos como sociais abordando precipuamente o avanço cada vez maior do comércio internacional através da globalização e das facilidades trazidas pela tecnologia.

\footnotetext{
${ }^{26}$ DI SENA JÚNIOR, Roberto. Comércio internacional e globalização: a claúsula social na OMC. Curitiba, Juruá, 2003. p. 97.
} 
Michel Rogalski ${ }^{27}$ sustenta que no contexto da economia globalizada, as mercadorias, os serviços e os capitais circulam livremente, enquanto o mercado de trabalho tende a permanecer mais restrito aos limites territoriais das nações, criando uma concorrência entre os trabalhadores, num plano mundial. A busca de mão-de-obra mais barata, por empresas multinacionais, em determinado país, pode destruir os empregos de outros. Por isso, os países desenvolvidos, preocupados com as consequências da concorrência comercial, passaram a acusar os países subdesenvolvidos de produzir com baixos salários e com precária proteção social, ou seja, de fazer dumping social, para rebaixar os valores de suas mercadorias nos mercados internacionais.

Desde 1993, dirigentes de nações desenvolvidas, especialmente da França e dos Estados Unidos, propugnam a criação de instrumentos de proteção de defesa do comércio em relação aos países subdesenvolvidos. Surgiu, então, a idéia de introduzir nos acordos do GATT uma cláusula social que estabelece condições sociais para o comércio exterior. Na realidade, essa cláusula social esconde seus reais interesses mercantis, porque, antes de tudo, trata de limitar a concorrência de produtos originários dos países do Terceiro Mundo. Constitui, portanto, numa barreira comercial entre os países do Norte e do Sul, para conter os efeitos advindos com a concorrência entre os trabalhadores em escala mundial ${ }^{28}$.

No Brasil, o governo se manifestou contra as restrições comerciais expressas na cláusula social da OMC, alegando que a definição de padrões trabalhistas seria uma forma de regular o comércio internacional.

Isto poderia criar uma infinidade de medidas e práticas protecionistas para salvaguardar os interesses unilaterais dos países desenvolvidos.

É controversa a questão da inserção de cláusula social nos contratos comerciais internacionais. Alguns entendem que ela representa uma tentativa de evitar o dumping social, o que levaria a uma competição mais equilibrada. Outros, no entanto, alegam que a cláusula social representa a punição dos países mais pobres e a perpetuação do desequilíbrio entre as nações, uma vez que penaliza aqueles setores da produção voltados para a exportação. No Brasil, observa-se que os produtos das indústrias de álcool,

\footnotetext{
${ }^{27}$ ROGALSKI, Michel. Clause sociale, emploi et comerce mondial. Recherches Internacionales, n. 50, aut. 1997.

${ }^{28}$ Cf. Responsabilidade social empresarial e combate ao trabalho infantil. Disponível em: 〈http://vlex.com/vid/80160507〉. Acesso em: 14. Ago. 2012.
} 
açúcar, cítricos, calçados e fumo tornaram-se alvo preferencial dos boicotes comerciais internacionais. Ou seja, os produtos das cadeias produtivas que têm demonstrado competitividade no mercado internacional ${ }^{29}$.

Neste diapasão, não se chegou ainda a um consenso mundial sobre a inserção ou não da cláusula social nos diplomas universais com o fim de padronizar os direitos trabalhistas no comércio internacional e com isso por fim à prática do dumping social.

\subsection{Dumping social e direitos humanos}

A prática do dumping social lesa os direitos fundamentais do homem, como o trabalho digno e altera o mercado mundial na esfera do comércio. A crescente prática do dumping social implica no desrespeito de direitos humanos, sobretudo de direitos trabalhistas, reforçando, portanto, a necessidade de regulamentação da matéria no intuito de inibir ou mesmo eliminar a prática de dumping social no processo produtivo. A regulamentação do dumping social reside na ideia de defender os direitos humanos.

As condições mínimas de trabalho estabelecidas internacionalmente surgem por força de sua dignidade própria, integrando o rol dos direitos humanos, em sua dimensão econômica e social.

Os direitos humanos, pautados nos valores da dignidade da pessoa, liberdade, igualdade e fraternidade que figuram como conquistas históricas definitivas da humanidade, reclamam um amparo mais vigoroso. Relativamente aos direitos econômicos, sociais e culturais não se pode admitir o retrocesso. Assim sendo, os documentos internacionais firmados pela OIT servem para proteger tais direitos, fazendo prevalecer os valores humanos, atuando como pauta para o princípio da justiça social, estabelecendo padrões de trabalho compatíveis com a excelência humana, como especificação dos preceitos pertinentes aos direitos humanos de caráter econômico e social.

Sendo assim, a regulamentação do dumping social começou a ser discutida para a proteção dos direitos humanos, no âmbito internacional, como forma de estabelecer proteção aos trabalhadores, inserindo padrões de trabalho dignos.

${ }^{29}$ Cf. Responsabilidade social empresarial e combate ao trabalho infantil. Disponível em: 〈http://vlex.com/vid/80160507〉. Acesso em: 14. Ago. 2012. 
A OIT atua na melhoria das condições de trabalhado e na valorização do trabalho, com a fixação de condições mínimas de emprego aplicáveis aos trabalhadores. Dentre muitos direitos humanos a serem observados, quando da regulamentação do dumping social, está a regulamentação das horas de trabalho, a fixação de uma duração máxima do dia e da semana de trabalho, do recrutamento da mão-de-obra, a luta contra o desemprego, a garantia de um salário que assegure condições de existência convenientes, a proteção dos trabalhadores contra as moléstias graves ou profissionais e acidentes do trabalho, a proteção das crianças, dos adolescentes e das mulheres, as pensões da velhice e da invalidez, a defesa dos interesses dos trabalhadores empregados no estrangeiro, a afirmação do princípio da isonomia salarial, a afirmação do princípio de liberdade sindical, a organização do ensino profissional e técnico, e outras medidas análogas.

Nesse aspecto, levando em conta a proteção dos direitos humanos, a OIT sofreu um grande avanço a partir do Pacto Internacional dos Direitos Econômicos, Sociais e Culturais, de 1966.

Para Flávia Piovesan ${ }^{30}$, o Pacto Internacional dos Direitos Econômicos, Sociais e Culturais, que atualmente contempla a adesão de 145 Estados-Partes, enuncia um extenso catálogo de direitos, que inclui o direito ao trabalho e à justa remuneração, o direito de formar e de filiar-se a sindicatos, o direito a um nível de vida adequado, entre outros. Desse modo, a efetivação dos direitos econômicos, sociais e culturais não é apenas uma obrigação moral dos Estados, mas uma obrigação jurídica.

Em 1998, a OIT aprovou a Declaração dos Princípios e Direitos Fundamentais dos Trabalhadores, que expressou os termos das Convenções sobre Liberdade Sindical, Livre Associação e Negociação Coletiva (Convenções 87 e 98), Eliminação das Formas de Trabalho Forçado (Convenções 29 e 1050), Eliminação do trabalho Infantil (Convenções 138 e 182), Eliminação da Discriminação no Emprego (Convenções 100 e 111). Essa Declaração de Princípios Fundamentais expressa o compromisso de todos os Estados-membros de uma padronização mínima nas relações de

${ }^{30}$ PIOVESAN, Flávia. Proteção internacional dos direitos econômicos, sociais e culturais. In: SARLET, Ingo Wolfgang (Org.). Direitos fundamentais sociais: estudos comparados de direito constitucional internacional. Rio de Janeiro: Renovar, 2003. p. 243-244. 
trabalho, a prevalecer, inclusive, sobre o mercado de comércio internacio$\mathrm{nal}^{31}$.

Sharon Hom cita cinco maneiras de análise para a relação existente entre direitos humanos e comércio internacional: a primeira delas defende que a política comercial não é uma política de direitos humanos, não estão vinculadas e nem devem estar; a segunda dispõe que se há conflito entre as matérias, os Direitos do Homem prevalecem; a terceira corrente coaduna com a tese de que se há igual valor entre os regimes, prevalecerá aquele que for determinado pela dinâmica institucional; já outra vertente entende que eles são interdependentes, pois a abertura dos mercados e o livre comércio promovem condições para o desenvolvimento e por isso alavancam o avanço dos direitos humanos; e finalmente, há aqueles que afirmam que a política comercial deveria ser usada como ferramenta bilateral e multilateral para impor o respeito aos direitos humanos.

Conforme exposto anteriormente, sob a ótica da relação internacional, deve-se analisar a inserção de cláusulas sociais para estabelecer uma coerência entre o comércio exterior e os direitos humanos, a fim de que haja a construção de um mercado internacional saudável.

O debate sobre a inclusão das cláusulas sociais na OMC e na OIT visa dar ênfase aos direitos sociais. Esta é a justificativa para a OIT ter adotado em 1998 a Declaração sobre Princípios e Direitos Fundamentais no Trabalho e seu surgimento, por ocasião da Conferência Internacional do Trabalho.

A interligação entre a OMC e a OIT seria não somente para o estabelecimento de relações comerciais mais justas, mas principalmente para uma efetivação do que é essencial ao homem trabalhador. Certo que não é fácil essa ação interligada, uma vez que os países envolvidos no comércio internacional parecem não jogar com transparência: os países desenvolvidos discursam em favor dos trabalhadores, quando intencionam barreiras protecionistas - acusam os países contrários; os países em desenvolvimento emperram a melhoria de suas condições de trabalho, para melhor competir no mercado - acusam os defensores da cláusula social. Nesses termos, os casos que desafiam o cumprimento dos direitos fundamentais dos trabalhadores seriam levados inicialmente à OIT, para uma solução negociada entre os Estados. Somente em casos de permanecer o descaso

\footnotetext{
${ }^{31}$ Cf. A cláusula social na OMC: por uma inter-relação efetiva entre OMC e OIT e o respeito aos direitos fundamentais dos trabalhadores. Disponível em: <http://vlex.com/vid/213031081> Acesso em: 14. Ago. 2013.
} 
com os direitos fundamentais dos trabalhadores, o fato seria levado à OMC, com decisão já tomada pela OIT de que as relações comerciais daquele Estado podem sofrer restrições, no sentido de penalizá-lo por concorrer no mercado internacional à custa da exploração vil de seus trabalhadores. Essa proposta evita deixar o Estado exportador inteiramente nas mãos do Estado importador, resguardando àquele contra medidas protecionistas deste, ao mesmo tempo em que reserva aos trabalhadores dos países exportadores a esperança de ver seus direitos, já reconhecidos no âmbito internacional, efetivamente garantidos ${ }^{32}$.

\section{O DUMPING SOCIAL SOB A ÓTICA TRABALHISTA NO BRASIL}

O dumping social gera danos à sociedade, danos esses que se não evitados são irreversíveis, razão pela qual o judiciário trabalhista vem buscando soluções para combater a prática do dumping social.

A concorrência deve ser feita, em um sistema capitalista, dentro das regras estabelecidas, em especial as de ordem pública, como as normas trabalhistas. Se uma empresa não observa de forma sistemática as leis trabalhistas, o preço de seu produto pode ser significativamente menor, prejudicando as empresas concorrentes, configurando, portanto, a concorrência desleal. Esta conduta deve ser coibida.

O dumping social trabalhista corresponde ao sacrifício do contrato individual de emprego em razão do lucro do empregador com desrespeito aos direitos trabalhistas.

Entre os direitos trabalhistas mais sacrificados com a prática do dumping social está a jornada de trabalho do empregado. Com o fito de produzirem mais e com um preço menor, os empregadores submetem os empregados a longas jornadas de trabalho, não respeitando o direito ao cumprimento de horas extras, férias ou intervalos inter ou intrajornada.

Nesse sentido, os juízes brasileiros, em especial o magistrado Jorge Luiz Souto Maior, esclarece:

\footnotetext{
${ }^{32}$ Cf. A cláusula social na OMC: por uma inter-relação efetiva entre OMC e OIT e o respeito aos direitos fundamentais dos trabalhadores. Disponível em: <http://vlex.com/vid/213031081> Acesso em: 14. Ago. 2013.
} 
As agressões ao Direito do Trabalho acabam atingindo uma grande quantidade de pessoas, sendo que destas agressões o empregador muitas vezes se vale para obter vantagem na concorrência econômica com relação a vários outros empregadores. Isto implica, portanto, dano a outros empregadores não identificados que, inadvertidamente, cumprem a legislação trabalhista, ou que, de certo modo, se vêem forçados a agir da mesma forma. Resultado: precarização completa das relações sociais, que se baseiam na lógica do capitalismo de produção. Óbvio que esta prática traduz-se como "dumping social", que prejudica a toda a sociedade e óbvio, igualmente, que o aparato judiciário não será nunca suficiente para dar vazão às inúmeras demandas em que se busca, meramente, a recomposição da ordem jurídica na perspectiva individual, o que representa um desestímulo para o acesso à justiça e um incentivo ao descumprimento da ordem jurídica". Por isso, continua o admirável jurista, "as práticas reiteradas de agressões deliberadas e inescusáveis (ou seja, sem o possível perdão de uma carência econômica) aos direitos trabalhistas constituem grave dano de natureza social, uma ilegalidade que precisa de correção específica, que, claro, se deve fazer da forma mais eficaz possível, qual seja, por intermédio do reconhecimento da extensão dos poderes do juiz no que se refere ao provimento jurisdicional nas lides individuais em que se reconhece a ocorrência do dano em questão. A esta necessária ação do juiz, em defesa da autoridade da ordem jurídica, sequer se poderia opor com o argumento de que não lei que o permita agir desse modo, pois seria o mesmo que dizer que o direito nega-se a si mesmo, na medida em que o juiz, responsável pela sua defesa, não tem poderes para fazê-lo. Os poderes do juiz neste sentido, portanto, são o pressuposto da razão de sua própria existência ${ }^{33}$.

${ }^{33}$ SOUTO MAIOR, Jorge Luiz apud CARVAS, Luiz Gustavo Abrantes. Desmistificando o dumping social. Jus Navigandi, Teresina, ano 16, n. 3014, 2 out. 2011. Disponível em: <http://jus.com.br/artigos/20121>. Acesso em: 29 ago. 2013. 
Ainda que não exista regulamentação específica no ordenamento jurídico interno brasileiro, é possível encontrar solução por meio de análise sistemática de vários dispositivos legais.

O artigo 404, parágrafo único, do Código Civil prevê o pagamento de indenização suplementar para compensar perda e dano, que pode advir, inclusive, da prática do dumping social. Tal indenização já encontrava respaldo nos artigos $652, d$, e $832, \S 1 .^{\circ}$, da CLT.

A Associação Nacional dos Magistrados da Justiça do TrabalhoANAMATRA, editou o Enunciado n. ${ }^{\circ} 4$, que prevê a possibilidade dos juízes trabalhistas imporem multas ou indenização suplementares às empresas que praticam o dumping social.

O texto do referido enunciado é utilizado ipsis literis por alguns magistrados trabalhistas brasileiros, sendo certo que várias empresas brasileiras já foram condenadas a pagar indenização aos seus trabalhadores ante a prática reiterada do dumping social, tendo em vista que, a empresa frauda a legislação social e às custas do prejuízo dos trabalhadores supera a sua concorrência.

DUMPING SOCIAL. DANO À SOCIEDADE. INDENIZAÇÃO SUPLEMENTAR. As agressões reincidentes e inescusáveis aos direitos trabalhistas geram um dano à sociedade, pois como tal prática desconsidera-se, propositalmente, a estrutura do Estado social e do próprio modelo capitalista com a obtenção de vantagem indevida perante a concorrência. A prática, portanto, reflete o conhecido dumping social, motivando a necessária reação do Judiciário trabalhista para corrigi-la. O dano à sociedade configura ato ilícito, por exercício abusivo do direito, já que extrapola limites econômicos e sociais, nos exatos termos dos arts. 186, 187 e 927 do Código Civil. Encontra-se no art. 404, parágrafo único do Código Civil, o fundamento de ordem positiva para impingir ao agressor contumaz uma 
indenização suplementar, como, aliás, já previam os arts. 652, "d", e 832, § $1 .^{\circ}$, da CLT. ${ }^{34}$

A melhor forma de inibir o dumping social é estabelecer sanção para as empresas que o praticam.

A maioria das condenações por dumping social se dá com relação à extensão da jornada de trabalho. Sabe-se que o dumping social afeta tantos outros direitos fundamentais, mas a maior preocupação, atualmente, que surge no âmbito trabalhista é em relação ao descanso do trabalhador e a excessiva carga de horas trabalhadas dentro da empresa. As jornadas excessivas de trabalho afetam substancialmente o desempenho do trabalhador. Submetê-lo a uma longa jornada de trabalho pode causar estresse e problemas de saúde ao empregado, além de um ambiente ruim dentro da empresa, principalmente com o próprio empregador.

No combate à prática do dumping social, na esfera trabalhista brasileira, admite-se em alguns casos a condenação na indenização pela prática de dumping social mesmo que a indenização não tenha sido pedida pelo trabalhador, sem que isso configure julgamento extra petita dos juízes nas sentenças trabalhistas.

Sobre o assunto, destaca-se o trecho do acórdão do recurso de revista . $^{\circ}$ 11900-32.2009.5.04.0291, de relatoria do ministro Walmir Oliveira da Costa, da Primeira Turma do Tribunal Regional do Trabalho da 4. ${ }^{\mathrm{a}}$ Região:

INDENIZAÇÃO POR DUMPING SOCIAL. CONDENAÇÃO DE OFÍCIO. JULGAMENTO "EXTRA PETITA" No julgamento do recurso ordinário interposto pelas reclamadas, o Tribunal Regional negou-lhes provimento, mantendo a sentença que as condenou, de ofício, ao pagamento de indenização pela prática de dumping social, no valor de $\mathrm{R} \$ 100.000,00$ (cem mil reais). ... Portanto, entende-se que, no caso, as reclamadas cometeram o denominado dumping social. Dessa forma, afigura-se razoável, diante da situação posta no processo, manter a Sentença que condenou as reclamadas,

\footnotetext{
${ }^{34}$ Enunciado aprovado na 1. ${ }^{\circ}$ Jornada de Direito Material e Processual, em 2007, realizada no Tribunal Superior do Trabalho.
} 
solidariamente, ao pagamento de indenização a título de dumping social. Entende-se razoável, também, diante das circunstâncias, manter o valor da condenação que foi arbitrado em $\mathrm{R} \$ 100.000,00$. Registre que a condenação solidária das reclamadas se justifica como forma de se coibir a conduta reiterada e sistemática de contratação de mão de obra irregular e precária, bem como para se coibir o agir do qual resulte em outras violações como as constatadas nos presentes autos e já referidas. Salienta-se, ainda, e de conformidade com o já exposto pelo juízo de primeiro grau, que não há falar em julgamento extra petita, diante dos fundamentos retro expendidos. Não há falar, também, em violação de dispositivos legais e constitucionais, principalmente os referidos nos recursos. Em relação à destinação do valor arbitrado a título de dumping social, é razoável que tal valor seja destinado ao "Fundo de Defesa dos Direitos Difusos", criado pela Lei 7.437/85, cujo objetivo é promover a reparação dos bens lesados e não sendo mais possível os valores devem ser destinados a uma finalidade compatível. Sobre a questão, lembre-se o artigo do Juiz Rodrigo Trindade de Souza, "PUNITIVE DAMAGES E O DIREITO DO TRABALHO BRASILEIRO: adequação das condenações punitivas para a necessária repressão da delinquência patronal.”. Condenação mantida ${ }^{35}$.

O combate ao fenômeno do dumping social inclui identificar os focos de sua atuação e com isso estabelecer uma punição das empresas responsáveis pela sua prática. Somente a aplicação das penalidades em face do dumping social é capaz de garantir o respeito pleno aos direitos trabalhistas.

Jorge Luiz Souto Maior aponta a indenização como sendo:

\footnotetext{
${ }^{35}$ BRASIL. Tribunal Superior do Trabalho. Dumping social: indenização deve ser requerida pelo ofendido. Disponível em: <http://www.tst.jus.br/home/-/asset_publisher/nD3Q/content/dumping-social-indenizacao-deve-ser-requerida-pelo-ofendido > Acesso em: 27. Ago. 2013.
} 
Em se tratando de práticas ilícitas que tenham importante repercussão social, a indenização, visualizando esta extensão, fixa-se como forma de desestimular a continuação do ato ilícito, especialmente quando o fundamento da indenização for a extrapolação de limites econômicos e sociais do ato praticado, pois sob o ponto de vista social o que importa não é reparar o dano individualmente sofrido, mas impedir que outras pessoas, vítimas em potencial do agente, possam vir a sofrer dano análogo ${ }^{36}$.

Atualmente há uma discussão sobre a destinação do pagamento das indenizações pelas empresas: se destinado a um Fundo ou fim social ou se destinado ao empregado que teve o seu direito lesado.

Há controvérsias entre os juízes trabalhistas, na medida em que muitos acreditam ser o dumping social uma violação aos direitos da sociedade, mais especificamente, direitos sociais, ao passo que outros entendem haver violação aos direitos individuais do empregado.

Decisão proferida pela 5. ${ }^{a}$ Vara do Trabalho de Porto Alegre, no estado do Rio Grande do Sul, adotou entendimento de que:

O valor deverá ser depositado em conta à disposição do Juízo e será utilizado para pagamento dos processos arquivados com dívida nesta Unidade Judiciária, a iniciar pelo mais antigo, observada a ordem cronológica, na proporção de no máximo $\mathrm{R} \$ 10.000,00$ para cada exeqüente ${ }^{37}$.

\footnotetext{
${ }^{36}$ SOUTO MAIOR, Jorge Luiz apud CHAVES, Maria Cláudia Gomes. Dumping social como fator de precarização das relações de trabalho. In: Âmbito Jurídico, Rio Grande, XIII, n. 78, jul 2010. Disponível em: <http://www.ambito-juridico.com.br/site/index.php?n_link=revista_artigos_leitura\&artigo_id=8087>. Acesso em: 27. Ago 2013.

${ }^{37}$ CARVAS, Luiz Gustavo Abrantes. Desmistificando o dumping social. Jus Navigandi, Teresina, ano 16, n. 3014, 2 out. 2011. Disponível em: 〈http://jus.com.br/artigos/20121〉. Acesso em: 29 ago. 2013.
} 
No mesmo sentido é o acórdão proferido no recurso n. $^{\circ}$ $71001281070^{38}$, que também entendeu ser cabível a indenização com destinação aos fundos sociais:

Por outro lado, Alexandre Chibante Martins entende que deve ser destinado o valor pago a título de indenização aos empregados, tanto é que, em sua decisão ${ }^{39}$, beneficiou o ex-empregado do Grupo JBS-Friboi. Segundo a fundamentação exposta no julgado: "foi ele quem sofreu o dano", e "não tem sentido destinar os recursos a um fundo social".

A discussão se vincula ao questionamento de ser o dumping social uma ofensa ao direito individual do trabalhador ou uma ofensa ao direito da sociedade, uma vez que sua prática lesa direitos sociais? A verdade é que o empregado teve seus direitos desrespeitados quando da prática de um ato ilícito pelo empregador, de modo que, a vítima direta da lesão é o próprio trabalhador.

O fato é que a questão da indenização por dumping social - chamada indenização suplementar - ainda tem grande amplitude e possibilidade de ser adotada pelo Judiciário brasileiro. Jurídica e socialmente embasado, existe uma margem ao arbítrio do juiz para aplicar a penalidade à empresa que burla inescusável e reiteradamente os direitos trabalhistas. Sem dúvida alguma, há certa contribuição ao combate à precarização da relação de emprego e, consequentemente, aos efeitos danosos causados em toda a sociedade ${ }^{40}$.

\section{CONCLUSÃO}

A prática do dumping social disseminou-se com o comércio internacional e seus efeitos devastadores são sentidos em todas as esferas. É

\footnotetext{
38 SEVERO, Valdete Souto. O dano social ao direito do trabalho. Disponível em: <http://www.amatra4.org.br/cadernos/265-caderno-15?start=3> Acesso em: 27. Ago. 2013.

${ }^{39}$ CARVAS, Luiz Gustavo Abrantes. Desmistificando o dumping social. Jus Navigandi, Teresina, ano 16, n. 3014, 2 out. 2011 . Disponível em: 〈http://jus.com.br/artigos/20121〉. Acesso em: 29 ago. 2013.

${ }^{40}$ CARVAS, Luiz Gustavo Abrantes. Desmistificando o dumping social. Jus Navigandi, Teresina, ano 16, n. 3014, 2 out. 2011 . Disponível em: 〈http://jus.com.br/artigos/20121〉. Acesso em: 29 ago. 2013.
} 
inegável que o fenômeno do dumping social está num processo de desenvolvimento crescente e, desta forma, os direitos humanos bem como os direitos trabalhistas estão sendo banalizados e desconsiderados.

O tema dumping social é complexo, pois envolve aspectos econômicos e sociais e, por esta razão, Organizações Internacionais, dentre elas o GATT e posteriormente a OMC e a OIT, se uniram para tentar combater e inibir a prática do dumping pela comunidade internacional.

Com a globalização, e consequente internacionalização da atividade comercial, as empresas começaram a se preocupar menos com a qualificação dos empregados e com os direitos humanos e trabalhistas de seus trabalhadores e passaram a desenvolver atividades econômicas buscando um custo de produção menor dentro da esfera do comércio mundial.

Nessa dinâmica, as multinacionais instalaram suas empresas em países em desenvolvimento, na busca de mão-de-obra mais barata e custo menor da produção, adotando normas e condições trabalhistas inferiores ao que seria um padrão razoável e aceito mundialmente.

A questão dos direitos trabalhistas e dignas condições de trabalho não podem ficar à margem de nenhuma negociação mundial, posto que são questões basilares para o desenvolvimento de um mundo mais justo e que respeita a dignidade da pessoa humana.

Nesse contexto, surgiram vários acordos internacionais na tentativa de instituir princípios e normas a serem seguidas pelos países. $\mathrm{Na}$ busca de uma padronização das relações trabalhistas atuaram a OMC e a OIT, na qualidade de órgãos competentes para regulamentar o dumping social no cenário internacional.

O tema da regulamentação do dumping social ainda não foi totalmente solucionado. Há alguns que defendem que a competência para tratar deste assunto seria a OMC, eis que ela trata dos assuntos comerciais, além de possuir um poder sancionatório que poderia ser imposto aos países que desrespeitassem as cláusulas sociais; já outros defendem ser a OIT, haja vista que ela trata dos assuntos trabalhistas no âmbito internacional.

A grande preocupação é com os países em desenvolvimento, pois, além de possuírem uma economia fragilizada, são os maiores prejudicados com a prática do dumping social, tendo em vista que a precarização dos direitos trabalhistas ocorre no local da prestação de serviços.

Surge, então, no contexto das Organizações Mundiais, especialmente OMC e OIT, a ideia de se instituir cláusulas sociais e códigos de 
conduta que fixariam os padrões de trabalho, os quais deveriam ser respeitados por todas as nações.

A controvérsia sobre a inserção de cláusulas sociais está envolvida na ineficiência das mesmas para resolver problemas sociais, satisfazendo mais interesses econômicos de multinacionais e de países desenvolvidos, não se traduzindo em uma forma de coibir a prática do dumping social.

Ainda que seja premente uma postura crítica e eficiente para coibir o dumping social, no judiciário trabalhista brasileiro somente alguns juízes têm defendido a condenação das empresas praticantes do dumping social ao pagamento de indenização aos seus empregados. Apesar de ser tímida a atuação jurisdicional, esta é essencial para identificar as empresas praticantes do dumping social e com isso estabelecer punições, imputandolhes o pagamento de indenizações.

No intuito de pacificar a aplicação de alguma sanção e seus desdobramentos é imperioso que haja regulamentação sobre o tema, com a adoção de instrumentos baseados nos princípios constitucionais, na jurisprudência pátria e nos Códigos de Conduta das Organizações Internacionais, aptos a erradicar a prática do dumping social, não somente em nome dos direitos humanos, mas também possibilitando o justo desenvolvimento econômico e social dos países.

\section{REFERÊNCIAS BIBLIOGRÁFICAS}

A cláusula social na OMC: por uma inter-relação efetiva entre OMC e OIT e o respeito aos direitos fundamentais dos trabalhadores. Disponível em: 〈http://vlex.com/vid/213031081> Acesso em: 14. Ago. 2013.

ALVES, José Augusto Lindgren. Cidadania, direitos humanos e globalização. In: PIOVESAN, Flávia. Direitos humanos, globalização econômica e integração regional: desafios do direito constitucional internacional. São Paulo: Max Limonad, 2002.

AMARAL JÙNIOR, Alberto do. Padrões trabalhistas e comércio internacional: renasce o protecionismo? In: BASSO, Maristela; PADRO, Maurício; ZAITZ, Daniela (ORG.). Direito do comércio internacional: pragmática, diversidade e inovação. Estudos em 
homenagem ao Professor Luiz Olavo Baptista. 2 tiragem. São Paulo: Juruá, 2006.

BASSO, Maristela; PADRO, Maurício; ZAITZ, Daniela (ORG.). Direito do comércio internacional: pragmática, diversidade e inovação. Estudos em homenagem ao Professor Luiz Olavo Baptista. 2. tiragem. São Paulo: Juruá, 2006.

BAPTISTA, Luiz Olavo. OMC e o comércio internacional: dumping e anti-dumping no Brasil. São Paulo: Aduaneiras, 2002.

BARRAL, Welber. Dumping e comércio internacional: a regulamentação antidumping após a rodada do Uruguai. Rio de Janeiro: Forense, 2000.

BARROS, Alice Monteiro de. Curso de direito do trabalho. São Paulo: $\mathrm{LTr}, 2005$.

BELLO, Marcia. Dumping social na esfera trabalhista. Disponível em: http://www.sjpmg.org.br/index.php/fique-por-dentro/artigos/1243dumping-social-na-esfera-trabalhista. Acesso em: 27. Ago. 2013.

BAPTISTA, Luiz Olavo. OMC e o comércio internacional: dumping e anti-dumping no Brasil. São Paulo: Aduaneiras, 2002.

BONAVIDES, Paulo. Do estado liberal ao estado social. 7. ed. Malheiros: São Paulo, 2001.

CARVAS, Luiz Gustavo Abrantes. Desmistificando o dumping social. Jus Navigandi, Teresina, ano 16, n. 3014, $\underline{2}$ out. 2011. Disponível em: 〈http://jus.com.br/artigos/20121>. Acesso em: 29 ago. 2013.

CHAVES, Maria Cláudia Gomes. Dumping social como fator de precarização das relações de trabalho. In: Âmbito Jurídico, Rio Grande, XIII, n. 78, jul 2010. Disponível em: <http://www.ambitojuridico.com.br/site/index.p hp?n_link=revista_artigos_leit ura\&arti go_id=8087 >. Acesso em: 27. ago 2013.

DI SENA JÚNIOR, Roberto. Comércio internacional e globalização: a claúsula social na OMC. Curitiba, Juruá, 2003.

DOMINGUES, Marcos Abílio. As relações de trabalho no mundo globalizado. In: BUENO, Roberto (Org.). Dilemas da globalização. São Paulo: Cultural Paulista, 2000.

DOMINGUES, Marcos Ab́lio. Introdução à teoria geral do direito do trabalho. São Paulo: LTr, 1999.

FACCHINI NETO, Eugênio. A função social do direito privado. Revista da Ajuris: doutrina e jurisprudência. Porto Alegre, v. 34, n.105, p. 153-188, mar. 2007. 
FIORATI, Jete Jane. Direito do comércio internacional: OMC, telecomunicações e estratégia empresarial. Franca: UNESP-FHDSS, 2006.

FIORATI, Jete Jane; BATISTA, Ana Carolina Marossi. Dumping social e sua disciplina no direito internacional. Revista de Estudos Jurídicos UNESP. Revista da Universidade Estadual Paulista. Franca, n. 10, ano 6, jan-dez 2001.

FRAHM, Carina; VILLATORE, Marco Antônio César. Dumping social e o direito do trabalho: direito coletivo do trabalho em uma sociedade pós-industrial. In: VIDOTTI, Tárcio José; GIORDANI, Francisco Alberto da Motta Peixoto (Coord.). São Paulo: LTr, 2003.

GONÇALVES, Reinaldo. $O$ Brasil e o comércio internacional: transformações e perspectivas. São Paulo: Contexto, 2000.

FREITAS JUNIOR, Antônio Rodrigues de. Os direitos sociais como direitos humanos num cenário de globalização econômica e de integração regional. In: PIOVESAN, Flávia. Direitos humanos, globalização econômica e integração regional: desafios do direito constitucional internacional. Max Limonad: São Paulo, 2002.

KANT, Emmanuel. Doutrina do direito. Tradução Edson Bini. São Paulo: Ícone, 1993.

KÜMER, Marcelo Barroso. As convenções da OIT e Mercosul. LTr: São Paulo, 2001.

MACHADO, Augusto. Da evolução do conceito de Subsídio no Gatt. Belo Horizonte: Faculdade de Direito da Universidade Federal de Minas Gerais, 1990.

MARX, Karl. A riqueza das nações investigação sobre sua natureza e suas causas. Vol. 1 São Paulo: Nova Cultural, 1985. 415p.

NASSER, Rabih Ali. A OMC e os países em desenvolvimento. São Paulo: Aduaneiras, 2003.

OLIVEIRA, Silvia Menicucci de. Barreiras não tarifárias no comércio internacional e direito ao desenvolvimento. Rio de Janeiro: Renovar, 2005.

PIOVESAN, Flávia. Proteção internacional dos direitos econômicos, sociais e culturais. In: SARLET, Ingo Wolfgang (Org.). Direitos fundamentais sociais: estudos comparados de direito constitucional internacional. Rio de Janeiro: Renovar, 2003.

Recommendations of the task force on aid for trade. (Recomendações do grupo de trabalho sobre a ajuda ao comércio) Disponível em: <www.wto.org>. Acesso em: 20. Jul. 2013. 
Responsabilidade social empresarial e combate ao trabalho infantil. Disponível em: 〈http://vlex.com/vid/80160507〉. Acesso em: 14. Ago. 2012.

ROGALSKI, Michel. Clause sociale, emploi et comerce mondial. Recherches Internacionales, n. 50, aut. 1997.

ROMITA, Arion Sayão. Globalização da economia e direito do trabalho. São Paulo: LTr, 1997.

SEITENFUS, Ricardo. Manual das organizações internacionais. Porto Alegre: Livraria do Advogado, 1997.

SEVERO, Valdete Souto. O dano social ao direito do trabalho. Disponível em: <http://www.amatra4.org.br/cadernos/265-caderno15? start=3> Acesso em: 27. Ago. 2013.

THORSTENSEN, Vera. OMC - Organização Mundial do Comércio: as regras do comércio internacional e a nova rodada de negociações multilaterias. 2. ed. São Paulo: Aduaneiras, 2001.

VARANDA, Aquiles Augusto. A disciplina do dumping do Acordo Geral de Tarifas Aduaneiras e Comércio: tipificação de um delito num Tratado internacional? Tese de doutorado. Faculdade de Direito da Universidade de São Paulo, 1987, 190 p.

XIRINACHS, José M. Salazar. The trade-labor nexus: developing countries perpectives. Journal of International Economic Law, v. 3, n. 2, June 2000. 
